\title{
Librarians as Scaffolders in Online Learning Environment: Access and Use of Information Resources and Services in Resources Constraint Setting
}

\author{
Gani Esther, Abdullahi I Musa, Abdulkareem Abubakar, Allahmagani Khali, Zaki Douglas Susan \\ Kaduna State University Library, Kaduna
}

\begin{abstract}
Online learning is no longer a story in educational institutions because of its high acceptance. A crucial area of interest in respect to online learning is access and utilization of information resources and services to the learners. In developed economies, various studies exist about information resources and services for online learnings, while for resource constrain settings limited research exist in regard to information resource and services for the learners. Grounded in Vygotsky social development theory, this study investigates the role of information professionals as scaffolders in supporting online learners' access and use information resources and services to ease learning. This study was framed in interpretative epistemology. A qualitative methodology and case study research design was adopted. Interviews were conducted with 11 online learners located in resource constrained setting in Africa-the National Open University of Nigerian, Kaduna study center. The study used thematic analysis process to identify 111 narratives. The narratives are organized into 5 major categories and further collapsed into three theoretical constructs explaining information professionals as scaffolders to aid access and utilization of information resources and services by the online learners.
\end{abstract}

\section{Introduction}

The use of online learning is by no means novel; it has been receiving lots of attention in higher education. In developing countries organized online learning is into three categories: (1) non-formal and adult education, (2) teacher training, and (3) higher education [1]. In Nigerian setting, these categories of online learners have taken advantage of information resources and services offered by libraries for improved learning outcomes. Hence, two critical issues are of recurring concern for online learners in resource constrained settings are the absolute nonuse, and the marginal use of information resources and information services offered by academic libraries in support of online learning. The absolute nonuse and marginal use of information resources and services result in poor comprehension and poor learning outcomes [2].

Even though the studies were conducted aiming at having a better understanding of information resources and services in an online learning environment, the problems of absolute nonuse and marginal use of information resources and services still remain. Improving optimal access and utilization of information resources and services in online learning environments in resource constrain setting calls for a fresh perspective. A potentially useful perspective is to embed librarians as instructive participants in an online classroom with the intent of providing scaffolding information support services to online learners. Librarians as scaffolders in an online classroom offer the much-needed academic support services to online learners. In education and learning, the concept of scaffolding support services has been advocated by scholars for decades. For instance, Bandura [12] and Vygotsky [13] social learning theories have stressed the critical need for a scaffolding during the learning process.

This study raised four fundamental questions: How do online learners in resource constrain setting access information resources in an online environment? What pedagogical challenges do online learners encounter in accessing and using information resources in resource constrain setting? What typologies of professionals do online learners consult for support during online learning in resource constrain setting? How does Vygotsky theory explain the role of librarians as scaffolders in an online learning environment?

This study has conceptual, and pragmatic significance. Conceptually, findings of the study are translated into a theoretical framework depicting information access and use by online learners in resource constrained settings. Pragmatically, findings of the study are potentially useful to policy makers and donor agencies with interest in the area of higher education in resource constrained settings.

\section{Theoretical Framework}

This section provides background on Vygosky's social learning - the theory adopted as a framework for the study. The section discussed an overview of the theory, followed by the construct of the theory. The section also provides an understanding of how the theory illuminate study on online information resources and services in online learning environment. 
The basic concern and purpose of this theory is knowledge construction through social interaction. The theory emphasizes the importance of what the learner brings to any learning situation as an active meaning-maker and problem-solver. The theory was built around some basic constructs. For the purpose of this study, all the three basic constructs were adopted: construct of MKO, construct of ZPD and construct of social interaction. These constructs are discussed below:

\subsection{Knowledgeable Other (MKO)}

The More Knowledgeable Other (MKO) construct is somewhat self-explanatory. It refers to anyone who has a better understanding or a higher ability level than the learner with respect to a particular task, process, or concept. The key to MKO is that they must have more knowledge about the topic or task being learned than the learner does. The MKO can raise the learner's competence through the Zone of Proximal Development (ZPD) [13].

\subsection{Zone of Proximal Development (ZPD)}

Vygotsky define the zone of proximal development as the distance between the actual development level and the level of potential development. In Vygotsky's theory, the level at which the learner can do or achieve a given task independently is identified by scholars as the learners' "level of actual development". It is at this level that a standard IQ test measure. More so, in Vygotsky's theory, what the learner can do in future after receiving help from $\mathrm{MKO}$ is known as the learners' "level of potential development". To further emphasize, the learner can only reach this level when he/she received assistance of the MKO [14] meanwhile, in between the level of actual development and the level of potential development of the learner is the Zone of Proximal Development (ZPD). This refers to the level or zone at where the learner cannot successfully perform or perform with difficulties a given task unless he is assisted by MKO. According to Vygotsky [3], it is at this level that learning takes place.

\subsection{Social Interaction}

According to Vygotsky's theory, much important learning by the children occurs through social interaction with a skillful tutor or More Knowledgeable Other (MKO). The social interaction occurs within the Zone of Proximal Development.

Some scholars adopted Vygotsky's theory to investigate issues related to online learning, information seeking and information searching.

\subsection{Previous Studies that Adopted Vygotsky Theory}

Vygotsky's ideas have been widely applied in the field of education. Several scholars adopted Vygotsky theory to investigate online learning from different disciplines. This section discussed some of the previous studies that adopted Vygotsky Theory of social development.

Garofolo [4] conducted a study using Vygotsky's theory to determine the difference in kindergarten literacy gain scores among students who attended public, private, and no preschool. The study adopted quantitative research methodology and survey research design. Questionnaire were used as an instrument for data collection for the study. The results showed a statistically significant difference for both the public and private preschool group compared to the no preschool group. Student achievement between the pre- and posttest increased the greatest for the public preschool attendance group. Results inform families' early childcare decisions, empower policy makers seeking early intervention, and contribute to the growing body of research acknowledging the positive effects of preschool attendance.

A study by Dafermos [11] attempts to analyze various types of the reception of Vygotsky's theory in the international Academic communities. The study develops a critical analysis of three widespread theoretical frameworks of interpretation of Vygotsky's theory: cognitivism, culturalism, cultural historical activity theory. It argues that fragmented readings of particular ideas of Vygotsky, without enough understanding of the theoretical programme in which these ideas have been included dominates in North-Atlantic research. The paper proposes the reconstruction of the theoretical programme of cultural historical psychology in the social and scientific context of its formation.

Another study conducted by Shabani [5] the study adopted Vygotsky's theory vividly to understand the professional growth of teachers in their work places. The study used quantitative research methodology and survey research design. Questionnaire were used to collect data for the study. The study concludes with a discussion of the various implications of the proposed approach for designing and implementing teacher professional development by linking the developmental aspects of professional development and core tenets of Vygotsky's developmental theories.

\section{Research Methodology}

The study adopted interpretive epistemology using social constructionism research philosophical paradigm. In line with social constructionism epistemology the research adopts a qualitative 
methodological approach. Qualitative methodology is a method of inquiry employed to gather an in depth understanding of phenomenon and human behavior especially feelings or experience and the reason that governs behavior. Qualitative methodology investigates theory development and testing, or simply as a tool for learning [6]. The purpose of this study is to understand the constraint do online learner experience in identifying and accessing information resources during online learning in their own settings.

However, in this research, case study research design was adopted for the study. A case study research design case study relies on multiple forms of data in order to build an in-depth case and usually select limited number of people as the focuses of study [7] Therefore, a case study research design is well-known to be best suited for this study this is because the purpose of this is to select limited number of respondents as a focus of the study. A total number of 11 participants were select out of 60 whom were selected through purposive technique particularly, criterion sampling. Purposive sampling involves selecting participants who are best able to help the researcher understand the problem and answer the research questions [9]. Therefore, respondents for this study must meet the following criteria: (1) must be a student of National Open University of Nigeria (NOUN) Kaduna Study Center (2) Who enrolled in online education (3) in 300 and 400 level students (4) class of 2016/2017. The NOUN Kaduna Center was chosen because, through the educational subsidy that they provide, they are known as populist and community academic institutions meant for online learning.

\subsection{Data Collection}

The data from this study was collected using insemi-structure interview. According to Dooly, [7] semi-structure interview permits the scholar and study participant to reconstruct the past, explain the present and envision the future. It also provides for in-depth understanding of the personal context within which the research phenomenon is located, and for very detailed subject coverage. The interview session began with administration of informed consent form. The consent form solicited participants' permission to voluntarily participate in the interview and it sought authorization to record the conversations. More so, respondents were assured of privacy and confidentiality concerning their responses. The interview was conducted at NOUN Kaduna Center. Questions were asked include how do online learners access information resources during online learning? What constraint do online learner experience in identifying and accessing information resources during online learning? The total duration of all the initial interviews amounted to 20 hours of conversations. During the interviews the researchers used probing technique to solicit for in-depth information and/or to build on their responses. This provided the researchers with rich in-depth information. By the time 11 participants were interviewed, the data was saturated. According to [8] saturation of data is the point when there are no new themes emerging from the data. The data were transcribed for analysis.

\subsection{Data Analysis}

In this study, the analysis of interview transcripts was based on inductive approach process through identifying patterns in the data by means of thematic codes. To accomplish these tasks, the researcher followed the three-phase procedure in thematic analysis as described by Miles and Huberman [10] which includes: (a) data reduction, (b) data display, and (c) conclusion drawing and verification. Using these three coding steps, the narratives were read and re-read thoroughly and considered significant statements narrated by respondents to develop meaningful themes that reports about access and use of information resources during online learning.

Table 1. Summary of data analysis

\begin{tabular}{|c|c|c|}
\hline Data Reduction & Data Display & $\begin{array}{c}\text { Conclusion } \\
\text { Drawing and } \\
\text { Verification } \\
\end{array}$ \\
\hline $\begin{array}{l}\text { Initial read and re- } \\
\text { read interview } \\
\text { transcripts while } \\
\text { searching for } \\
\text { similarities and } \\
\text { differences in } \\
\text { themes by } \\
\text { underlined using } \\
\text { pen (open code). } \\
\text { Recoded in plain- } \\
\text { sheets of paper. } \\
\text { The aim is to } \\
\text { condense the data } \\
\text { into a smaller and } \\
\text { more manageable } \\
\text { size. }\end{array}$ & $\begin{array}{l}\text { Data } \\
\text { began by listing } \\
\text { all the codes and } \\
\text { creating meaning } \\
\text { out of relevant } \\
\text { text regment } \\
\text { (open codes) } \\
\text { Narratives coded } \\
\text { into } \mathbf{1 1 1} \text { open } \\
\text { codes. Related } \\
\text { open codes were } \\
\text { identified and } \\
\text { grouped together } \\
\text { to form sub- } \\
\text { categories. } \mathbf{1 3} \\
\text { sub-categories }\end{array}$ & $\begin{array}{l}18 \text { number of sub- } \\
\text { categories labels } \\
\text { and narrowing } \\
\text { down to final } \\
\text { overarching themes } \\
\text { or categories into } 7 \\
\text { emergent categories } \\
\text { (wider categories). } \\
\text { The final categories } \\
\text { were then narrowed } \\
\text { and fitting wider } \\
\text { categories into } 3 \\
\text { theoretical } \\
\text { constructs. }\end{array}$ \\
\hline
\end{tabular}

Source: Summary of data analysis adopted from Miles and Huberman [10]

The narratives were coded into 111 open codes (meaning derived directly) recoded in the spreadsheet. The 111 open codes were condensed into 13 lower categories and identified as classification subcategories. The classification subcategories were then further collapsed into 7 emergent categories. The strategy for the data analysis is summarized in the table below as adopted in this study from Miles and Huberman [10]. 


\subsection{Description of Emergent Categories}

This section describes the seven (5) categories and eighteen (11) sub-categories that emerged from the three hundred and eleven (111) open codes. The categories, sub-categories and quotations were arranged properly. They are presented in this style to allow the reader an opportunity to draw on the reflection of thought given to the participants' responses. The section is also organized based on questions asked in the process of data collection.

\section{Findings}

Data in form of phrases and sentences on how online leaners access and use information resources and services were collected from 11 respondents. The responses provided multiple views on how online learners in NOUN Kaduna Study Centre access and utilize information resources and services.

\subsection{How Online Learners Access and Utilized Information Resources}

To uncover how the online learners access and use information resources, students from NOUN Kaduna study centre were asked to discuss how they access information. Three categories emerged in their evaluation on how they access information, which are subsequently discussed.

Virtual Class: in this research sub category it is found that respondents engaged access and use information through on-line discussion forum on research, academic advising, and group tutorial during preparation for online examinations. The class on-line discussion focuses on important academic advising especially during course registration process, assignments and test. Other major ways to access and use information on the online discussion is on tutorials on various courses and how to answer questions on the tutor mark assessment. One respondent who is in $400 \mathrm{~L}$ recounted that 'I access information on our forum on research topics and steps to writing proposal which is helping me in my project" A 300L respondents explained that "during our virtual class discussion, we seek for advices from one other on how to register for courses especially on picking elective courses.

Face to Face: This sub category includes narratives related to how the online learners access and use information resources and services via the face to face academic activities that the NOUN students are engaged in; which are Orientations, industrial training, workshop and seminars. Students interviewed are engaged in a compulsory 6-month industrial training to any institution of one's choice. Some respondents both in 400L elucidated that "we are engaged in a 6 month compulsory training in various organization, there we are expected to record or document every activity of the organization that gives us the opportunity to gather a lot of information" in addition others 400L student described that "During our industrial training we are treated like staff of the organization because we have all the information we needed but strictly under supervision from both the organization and our university" Some 300L students narrated that "before or during the workshop, all the information we needed is made available, we are engaged in workshop activities which is a short training process organized by different faculties".

\subsection{Type of Information Resources They Access and Consult}

In order to ascertain the type of information resources that are accessed and consulted by the online learners; the students from NOUN were asked to describe the information resources they access and use during online learning. From the 11 respondents, two categories of the type of information resources accessed emerged; which are hard copy and soft copy.

Hard copy: the findings revealed that respondents use hard copies of information such as textbooks, journals and other information resources like dictionaries and encyclopedias. In some cases, this hard copies of information are purchased by the students as personal study items. As a 300L respondent explained, "I bought some textbooks and a dictionary for my personal use" this was confirmed by another respondents, "for my private use, I just buy some recommended books in case of lack of electricity, I just use my books."

Soft copy: This sub category is the evaluation of the type on soft copies of information resources accessed by the online learners. Findings indicated that the respondents access soft copies of electronic course material (modules), database, and information on websites. Others are tutor mark assessment (TMA) resources, online reference resources, and examination guide. Some 400L online learners narrated that "the first thing we do immediately after registration is to download all our course materials or modules from our registration portal and resources like statistics, handbooks and dictionaries".

\subsection{Challenges Faced in Accessing Information Resources}

To uncover the challenges faced by the NOUN student in accessing information resources, the students were asked to describe the problems they encounter as online learners. The objective of this is to understand the common challenges that they face. 
From the responses gotten three categories of challenges emerged from the 11 respondents. They are Infrastructural challenges, Problem of information literacy, and Financial constrain as discuss below.

Infrastructural challenges are the various challenges that that student of NOUN, Kaduna Center encore with the various facilities needed in accessing information resources electronically. Some of the challenges hinder student from making use of resources that are on the NOUN portal. The sub categories generated from respondent under this category included

Unreliable internet services refer to difficulty or constrain encounter while using the internet for browsing. Such constrain ranges from low bandwidth, peak hour that prevent users from accessing needed information or submitting their TMA's. Respondent views on this constrain was as follows, 'most times accessing information is poor in my area due to unreliable internet services'.

Epileptic electricity services are a challenge peculiar with developing countries, electricity supply is erratic not available twenty-four hours (24 hours) like other country were power supply is constant. Individuals, business and corporate institution have to depend on alternative power supply (generator) for various task. A respondent complaint, some time I can't access information nor submit my TMA due to power outage, I have to wait for light since I can't afford a generator'.

Inadequate information literacy refers to the inability of respondent to search and use information because the lack information literacy skills like the ability to access, evaluate, use and retrieve information resources. Some 400L of the respondent narrated that since most of the information resources (hardcopy) are not given to me before exams, I then to compress my TMAs as reading resources for my exams in the absence of course modules".

High cost of required text refers to expensive cost of running an On-line Course. Student of on-line course in NOUN Kaduna study centre lamented that aside from the school fees which is paid at the beginning of each semester. A 300L respondent narrated that 'in my group of ten only I had the facility to access Information resources, download, print as hard copies for my group discussion/ tutorial members because I am opportune to work in an office were those facilities are available, most of my course mate cannot afford additional cost of accessing information resources electronically'.

\subsection{Professional that Have Assisted}

To uncover professionals that assisted the NOUN students of Kaduna study centre, respondents were describe certain personnel of the NOUN Kaduna study center who assisted them. The objective is to understand the professionals who assisted the online learners of NOUN. Respondents were asked to describe the professionals that gave them assistance in the course of their study. Looking at the result, three categories of professionals that assisted emerged which are ICT staff, Level coordinators and Course mate and Graduate colleagues from the 11 respondents and are described.

ICT staff: one of the most common professionals that assisted the NOUN online learners are the ICT staff. The ICT include the director, Management Information System (MIS) staff, Network maintenance staff, and data officer. Some respondents communicated that "as most on our activities are done online, we get help regularly from the ICT staff especially on the issue of information resources download and online registration process.

Level coordinators: another professional that assisted the online learners are their various level coordinators. In this sub category the one respondent stated that "I depend mostly on my level coordinator for all important information in respect to TMA, registration and examination update."

Course mate and Graduate colleagues: this sub category reflect that course mate and graduate colleagues are part of the professionals that assist the online learners. Most of the respondents noted due to contacts of all course mates including graduate students available online it is easier to assist each other. One respondent narrated that "it is much easier to contact my course mates and graduates from the school in good time through their contact addresses and phone numbers'.

\subsection{Experiences with Information Profes- sional or NOUN Library, Kaduna Study Centre}

To uncover the experiences that the online learners have had with the professional librarian or library. The respondents were asked to narrate the experiences of the librarian or library. The objective is to understand the common experiences of the online learners from the librarian or library. The sub category was discussed below.

Information professional only provide past question paper, Colleagues and graduate students are more accessible, they are not aware of the services of the professional librarian, and to read and write exams information professional only provide past question paper. This sub category includes narratives of respondent to their experiences with NOUN library. Their reason for visiting the library is to get access to previous question papers that would enable them practice for exams. Some 300L respondents narrated that 'The only reason I go to the library is to collect past question paper for my exams'.

They are not aware of the services offered in the librarian: in this sub category a respondent 
explained that they lacked proper orientation on the use of library, hence are not aware of the various services provided by the library. A $400 \mathrm{~L}$ students asserted that "as my studies is done online, am not aware of the librarian or the library".

\section{Discussion of Findings}

The discussion of findings was arranged in line with the three theoretical constructs.

\subsection{Social Interaction}

Findings from this study revealed that online learners interacted and share knowledge through Virtual discussion. Further findings from the study also revealed that Students from NOUN engaged in on tutorials of various courses and discussed on how to answer questions on the tutor mark assessment. Another finding from this study revealed that NOUN students are engaged industrial training, workshop and seminars.

\subsection{More Knowledgeable Other (MKO)}

Three major aspects were identified as more knowledgeable others which are ICT staff, Level coordinators and course mates and graduate colleagues. Findings from the study revealed that ICT staff were in charge of managing all learner's information, maintaining the network and in charge of online examination. The professionals that really assisted the online learners as well are level coordinators, course mates and graduate colleagues.

\subsection{Zone of Proximal Development (ZPD)}

This study also identifies challenges faced in accessing Information resources by the online learners in NOUN, Kaduna study centre to include, Infrastructural challenges, Problem of information literacy, and Financial constrain, Unreliable internet services, problem of information literacy, Epileptic electricity service. For instance, the online learners depend greatly on the internet to access information, in some cases they faces with the challenges of search skills thereby not knowing which information best suit a particular assignment.

\subsection{Experiences with professional librarians or NOUN Library, Kaduna Study Centre}

The only experience the online learners of the NOUN Kaduna study have had with a librarian is that Librarian only provide past question paper. The learners are not even aware of the services that a librarian can offer. For instance, the online learners prefer to access information from their colleagues and graduate students than the librarian because the librarian is not accessible.

\section{Conclusion}

From the findings of the studies it showed that online learners in resources constraints settings are not aware of various services that the information professionals offer on NOUN Kaduna study centre. Since the impact of the information professional is not felt by the online learners therefore, it is recommended that information professionals should act as scaffolders in providing proactive, innovative and creative resources and services to the online learners.

\section{Future Work}

Since the library is the hub of knowledge a study is relevant showcasing what the library can offer to the online learners in NOUN Kaduna study centre. Generally based on the fact that this research focuses on NOUN Kaduna study centre only, it can be applied to other study centers in resources constraint settings.

\section{References}

[1] Wiedrick J., (2015) Learning Forward: learning Professional Association retrieved from https://learningforward.org/standards/learningcommunities /john-wiedrick

[2] Hung, H. T., (2015). Flipping the classroom for English language learners to foster active learning. Computer Assisted Language Learning, 28(1), $81-96$.

[3] Vygotsky, L. S., (1987). Thinking and speech. In R. W. Rieber \& A. S. Carton (eds.)., The collected works of L. S. Vygotsky. Vol. 1. Problems of general psychology (pp. 39285). New York: Plenum.

[4] Garofolo, M.S., (2017) Effect of Public and Private Preschool Attendance on Kindergarten Literacy: Dissertation Submitted in Partial Fulfillment of the Requirements for the Degree of Doctor of Education, Walden University.

[5] Shabani, K., (2016) Applications of Vygotsky's sociocultural approach for teachers' professional development. Shabani, Cogent Education (2016), 3: 1252177http://dx.doi.org/10.1080/2331186X.2016.125217 7.

[6] Unamuno, V., Patiño, A., (2017). Producing knowledge about plurilingualism with young students: a challenge for collaborative ethnography. In E. Moore \& M. Dooly (Eds), Qualitative approaches to research on plurilingual education (pp. 129-149). Research-publishing.net. https://doi.org/10.14705/rpnet.2017. 
[7] Dooly, M., (2017) A Mediated Discourse Analysis (MDA) approach to multimodal data. In E. Moore \& M. Dooly (Eds), Qualitative approaches to research on plurilingual education (pp. 189-211). Research publishing.net. https://doi.org/10.14705/rpnet.2017.

[8] Dooly, M., Moore, E., \& Vallejo, C. (2017). Research ethics. In E. Moore \& M. Dooly (Eds), Qualitative approaches to research on plurilingual education (pp. 351362). Research-publishing.net. https://doi.org/10.14705/r pnet.2017.

[9] Moore, E., \& Llompart, J. (2017). Collecting, transcribing, analyzing and presenting plurilingual interactional data. In E. Moore \& M. Dooly (Eds), Qualitative approaches to research on plurilingual education (pp.403-417). Research-publishing.net. https:// doi.org/10.14705/rpnet.2017.

[10] Miles, M.B., Huberman, A.M., (1994). Qualitative Data Analysis (2nd edition). Thousand Oaks, CA: Sage Publications.

[11] Dafermos, M., (2016). Critical Reflection on the Reception of Vygotsky's Theory in the International Academic Communities. Kul'turno-istoričeskaâ Psihologiâ, Volume 12, Number 3, pp. 27-46(20), Publisher: Directory of Open Access Journals. DOI: https://doi.org/10.17759/chp.2016120303.

[12] Bandura, A. (1989). Social cognitive theory. In R Vasta (Ed.), Annals of child development. Vol.6. Six theories of child development Greenwich, CT: JAI Press, 1-60. From: http://www.uky.edu/ eushe2/Bandura/ Bandura1989ACD.pdf.

[13] Vygotsky, L. S., (1998). Infancy. In Rieber R. W. (Ed.)., The Collected Works of L.S. Vygotsky (207-241). Vol. 5. Plenum Press, New York.

[14] Kearsley, G., (2005). Social Development Theory. Theory into Practice Database. [Online], http://tip.psychology.org/vygotsky.html (Access date: 12 November 2015). 